\title{
Planning the integration of new technologies for sustainability: case study of a school building's restoration project in Rome
}

\author{
L. de Santoli, F. Fraticelli \& F. Fornari \\ CITERA department, University of Rome "La Sapienza", Italy
}

\begin{abstract}
The research for sustainability challenges us to reconsider the way we think about architecture and offers great opportunities to renew its formal language with new technologies, as it did in the beginning of the 1900s with the introduction of reinforced concrete, steel and glass in modern architecture. We need to transform the architectonic envelope in a smart skin, a selective filter with the capacity to control the energy fluxes between indoor and outdoor environments, to change its working according to different weather conditions and to fully exploit renewable resources. This can be done with new technologies that must be integrated in constructive systems in order to combine the enhancement of energetic efficiency with aesthetic requirements, which is even more important in building restoration, whose landmark preservation principles are more restrictive. Planning the integration is the theme of the research, performed on a school building restoration project, built during the $1980 \mathrm{~s}$ in the periphery of Rome. This building is a representative model in terms of time of construction, typology, constructive technologies, dimensions and energy consumption; therefore, it can roughly describe $60 \%$ of Roman schools, whose total estate is of 13.5 million cubic meters in 1,296 buildings.
\end{abstract}

Keywords: green building technologies, BIPV, integration of photovoltaic, solar design, sustainable architecture.

\section{Introduction}

Almost $35-40 \%$ of energy consumption in Europe [1] is due to buildings and, in view of the technologies available, it forms the field with the widest room for improvement in energy savings. The enhancement of energy efficiency in 
buildings is therefore the most important field of research for a sustainable development of our society and also represents a great chance for architecture to renew its formal language through the integration of new technologies and new materials in building construction and the development of an environmentalfriendly planning. This task involves the definition of new standards for the construction of new buildings and, even more importantly, the renovation of existing structures, with two different approaches: the managing of financial incentives for private buildings and the development of restoration projects for public buildings that are important not only because of their low energy rating, but also for their capacity to spread a new style of living based on ecological responsibility. In the public estate, excluding those building types dispensed from meeting energy standards (according to the Italian law Dlgs 311/2006: hospitals, prisons, barracks), $75 \%$ of energy consumption is due to schools [2].

School buildings are also interesting because of their need to strike a balance between cost reduction and high levels of comfort, necessary to create a warm and welcoming indoor environment in order to make children feel that the space is their own. As a matter of fact, it has been experimentally proved [3] that comfort conditions can play a key role for children in learning and developing their own capacities to the maximum, this influence can be even stronger than on adult office workers' performance. Finally, school building renovation projects can give us the opportunity to introduce environmental and energy information into the education process with a concrete example that can be easily experienced not only by children, but also by the whole neighborhood.

\section{Defining the case study}

The research has been performed on a school building, built during the 1980s in Tor Bella Monaca, a peripheral quarter of widespread and economic public housing in Rome, characterized by a deep urban degrade.

This building offers us a representative model of typology, constructive technologies, dimensions and energy consumption of roughly $60 \%$ of Roman schools, whose total estate comprises 13.5 million cubic meters in 1,296 buildings [4]. As a matter of fact, $60 \%$ of these schools have been built in the last 40 years in observance of standards set by the ministerial decree 18/12/1975 "Updated technical regulations concerning school buildings" (original title is: "Norme tecniche aggiornate relative all'edilizia scolastica"), published to achieve indoor comfort and cost reduction. Though this law exerted a positive influence on building design (of course, proportional to the technological and environmental knowledge of '70s), the lack of control in building construction and management (due to the weakness of the administration, interested only in reducing costs and not in broad-based projects), has led to the present situation in which even the high amounts spent on energy do not ensure the necessary thermal, visual and acoustic comfort. Therefore the building restoration project must recognize the potentialities of the existing construction and improve them in order to reach a new synthesis where comfort and reduction of energy consumption can be achieved. 


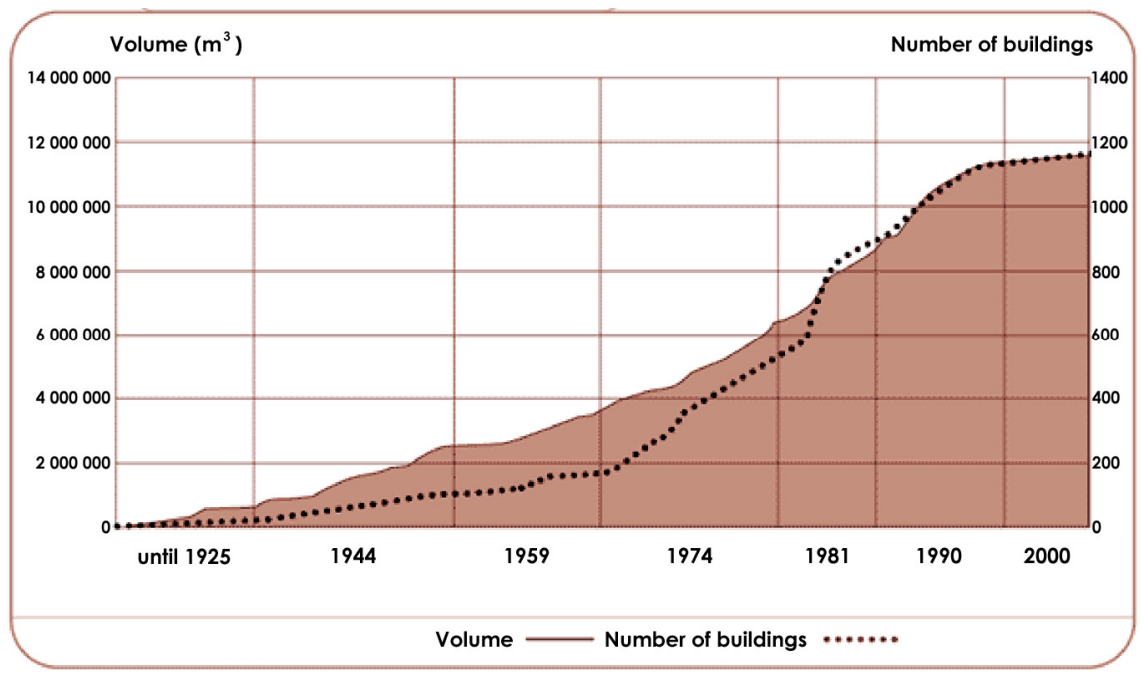

Figure 1: Trend growth of Roman public school constructions, in terms of volume and number of building; source: municipality of Rome, V department.

\section{Objectives}

The building chosen as object of our study presents many favorable aspects for a bioclimatic handling; this can be seen mainly in the almost exclusively southfacing orientation of the classrooms and laboratories and in the use of massive walls and large, windowed surfaces on the south façade. These solutions testify to the desire to take full advantage of solar radiation for the heating and illumination of the classrooms in the winter seasons and to limit it in the summer, through the heavy walls, capable of delaying the thermal wave until hours of non-usage of the school's interior, and of offering shade for the windowed surfaces.

The renovation project of the building thus should fully exploit these potentialities of the building, while overcoming critical factors, consisting mainly in the poor thermal performance of the building envelope and in the absence of effective shading systems. In fact, the only existing shading system, made of PVC roller blinds, does not allow for selective shading, capable of reducing the effects of glare in the winter season and the greenhouse effect in the summer. For this reason the roll-up shutters often remain closed, with an ensuing great loss of thermal energy in winter and of natural lighting throughout the whole year, resources which are free and - in the case of lighting - of better quality.

The project comprised common operations, such as the creation of a continuous external insulation, the replacement of windows and doors, the substitution of the boiler with a new, high-efficiency one and the fitting of 


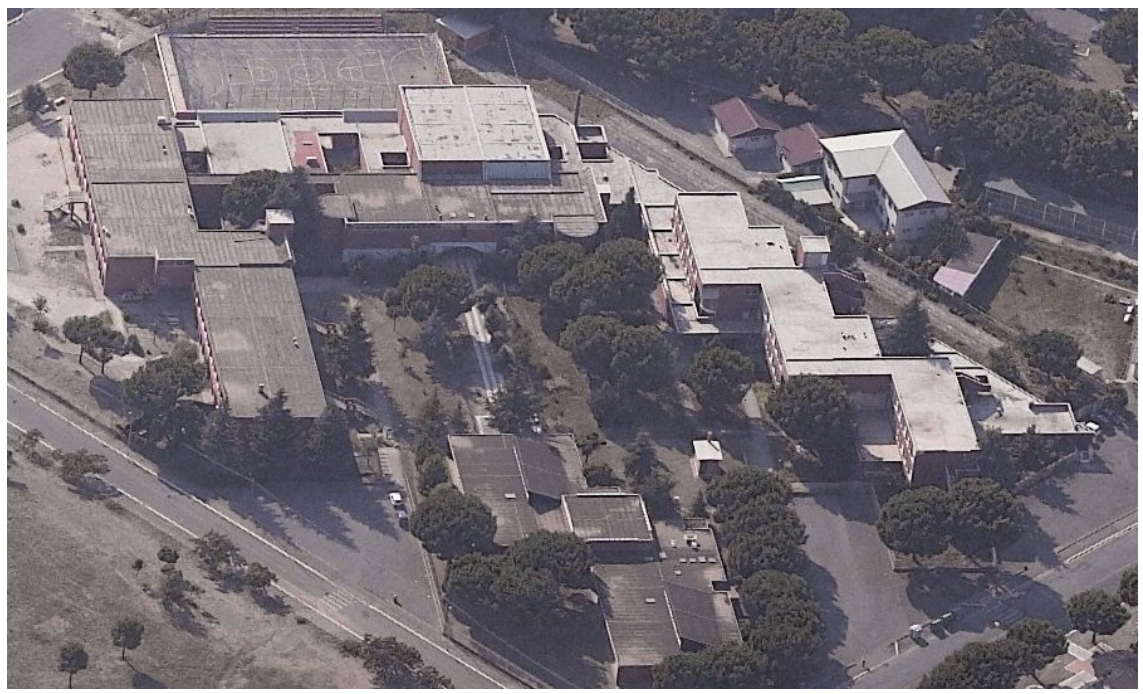

Figure 2: $\quad$ East view of the school.
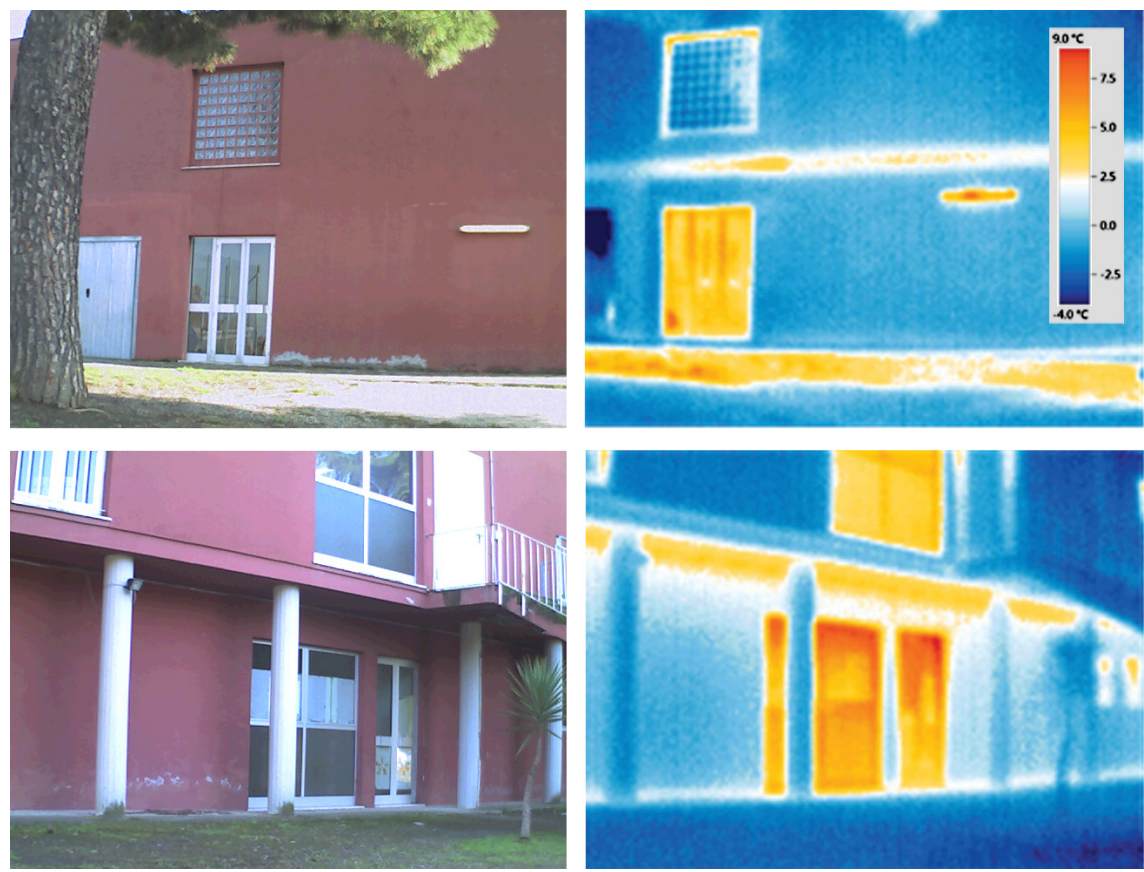

Figure 3: Infrared thermographic measurements of thermal bridges. 
thermostatic valves for a better handling of the heating system. In addition, it focused on the project of the shading system, in order to obtain a selective filter that should regulate the incoming of thermal and luminous radiation.

The shading system, furthermore, could include in its interior the photovoltaic technologies for the production of electric energy. In this way we obtained a photovoltaic system fully building-integrated, both on the technological as well as aesthetic level, still guaranteeing the advantages proper to non-integrated systems, consisting in the optimized orientation of the modules (in this case we could even adopt a tracking strategy to optimize the radiation that hits the cells), in their easy maintenance and (if necessary) replacement and in the reduction of losses due to overheating, thanks to the optimal ventilation on modules' rear surface.

Today the insertion of these technologies seeks exclusively to reduce their impact, attempting not to disturb a pre-established situation. In this study, the potentialities of integration were explored, as a possibility to enrich the architectural language with new "architectural terms": in the case in question, the new structures should take up the rhythms of the façade, underlining them while enriching the external appearance with a light and technological element.

\section{Planning the integration}

Each intervention has thus been evaluated under a group of diverse aspects: technical, formal/aesthetic, economic and energy output.

The global improvement in thermal performance of the architectural envelope, accomplished through external insulation and replacement of the frames, achieved a drastic reduction of heat dispersion through the envelope (up to $1 / 4$ of the previous state) and guaranteed greater interior comfort by reducing the thermal gradient, the cold surfaces, and the draught. The installation of the external wall insulation has furthermore allowed us to redesign the façade, without altering its fundamental characteristics: underlining the internal division of spaces and the repetition of the tripartite rhythm, greater transparency and familiarity were sought, as well as a more recognizable appearance to the school building for the children, so that in this way they could recognize the spaces as their own.

Initial energy consumption, estimated by comparing calculations with measured data, and equal to $12.8 \mathrm{kWh} / \mathrm{m}^{3}$ was reduced to 2.8 , with a subsequent passing from energy class $\mathrm{D}$ to $\mathrm{A}+$.

Regarding the summer season, the restoration project guarantees a better performance of the envelope in terms of phase displacement (from 6 to 10.5 hours) and damping (from 0.64 to 0.11 ) of the thermal wave, taking advantage of the pre-existing wall mass to delay until the off-hours, when the internal spaces are not in use, those peak charges, which can be disposed of using the openings already present in the skylights and internal courtyards.

The project of the shading system, the technological components with the strongest impact on the existing structure, was studied in particular depth through a comparison between the various options of two basic solutions: a 


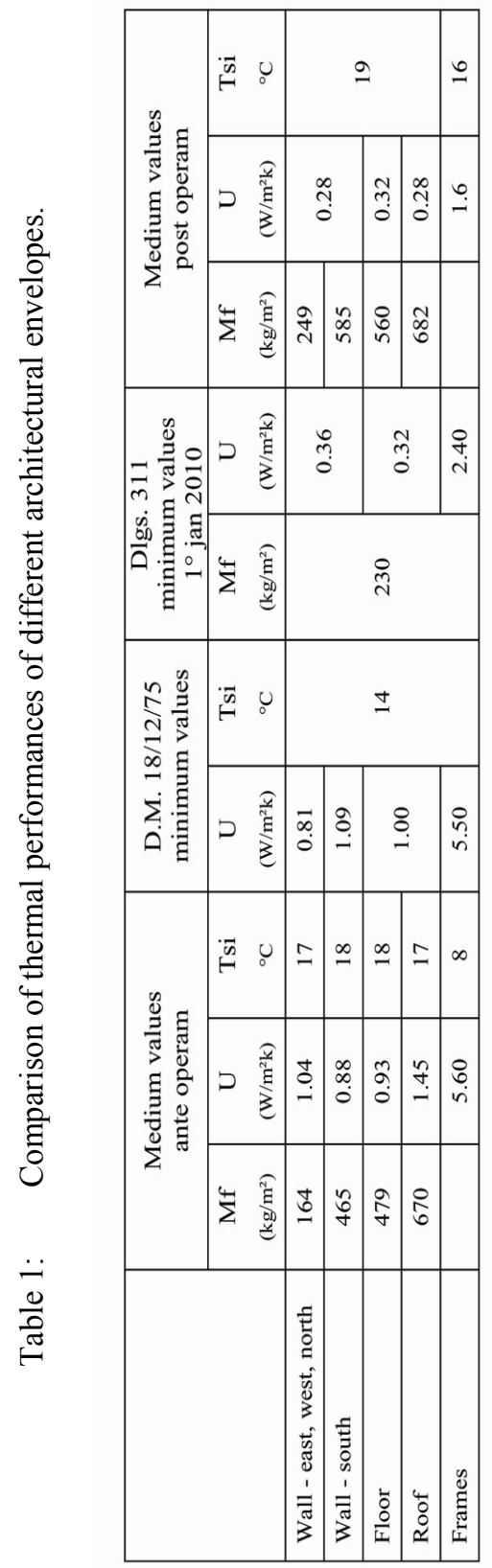



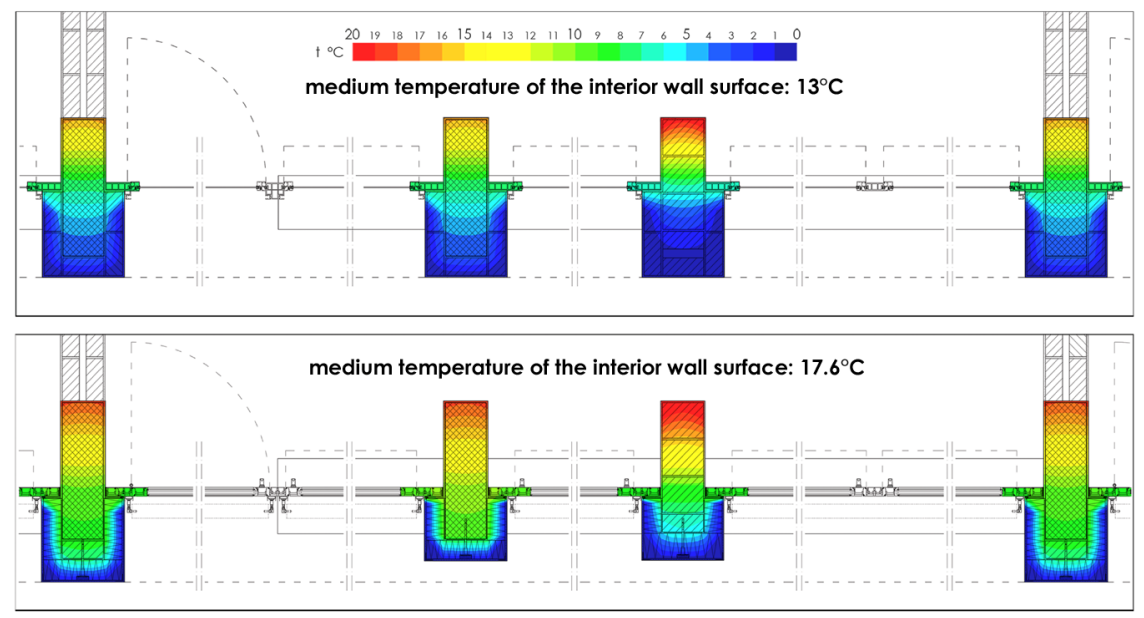

Figure 4: Temperature gradient in the south wall's depth before (above) and after (below) renovation.
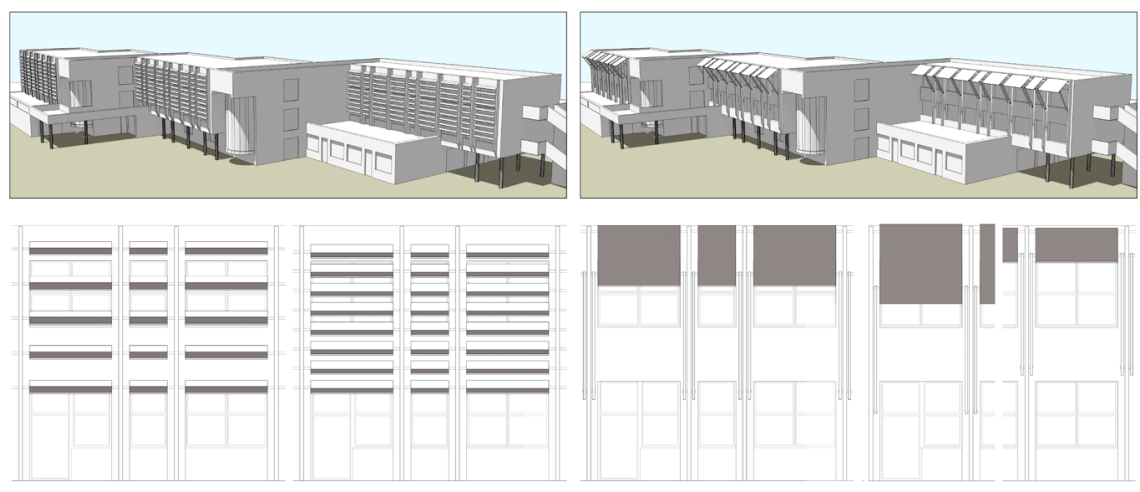

Figure 5: Comparison of aesthetic qualities between the "blades" (on the left, two different steps) and the "cantilever solar screen" (on the right, one fixed and one with tracking systems).

system of "blades" and one of a "cantilever solar screen" over each window; these different styles have been evaluated on the basis of their aesthetic integration, energetic output and shading performance from luminous and thermal radiation.

On the aesthetic level, in the first place the steps of the structure were defined in relation to the façade, with its tripartite rhythm of openings, in the second place, the comparison between the various systems has shown how the blade system adapts itself poorly to the building in question inasmuch as too sparse (and thus lacking its own formal dignity) or too thick and thus incapable of entering into dialogue with the façade behind it, and of guaranteeing the 
transparency required of a school building in order to offer an image of the school's openness and full accessibility to the urban context. The cantilever system, instead, is applied to the existing structure without denying it, and as an element possessing its own formal dignity that allows for a full visual transparency.

In regard to the energetic production, as well, the cantilever system guarantees a greater performance because it does not affected, as occurs with the blade system, from shade afforded by various wings of the building, which cause in the latter a loss of productivity of roughly $6 \%$ in terms of $\mathrm{kWh} / \mathrm{kWp}$ or of $11 \%$ in terms of total active surface, should one decide to utilize only the best exposed surface of the blades as active. The cantilever system furthermore can also be applied to the north façade to obtain a covered pathway of access to the school, with an increase of the available area of roughly $30 \%$, thus satisfying $53.6 \%$ of the building's total electric energy requirements.

The hypothesis of tracking systems - which in this case (W-E axis) can be daily or seasonal - has proven to be of scarce efficacy inasmuch as it offers reduced advantages, on the order of $3-5 \%$, which corresponds roughly to the energy necessary to run the modules.

With regard to shading capacity, the cantilever system, performing in a less linear way between the winter and summer situations, guarantees a greater selectivity in transparency while the blade system has the defect of casting a heavy shadow even in winter, due principally to the fact that in order to optimize the energy output, the blades would be placed with a tilt of $30-34^{\circ}$ and thus
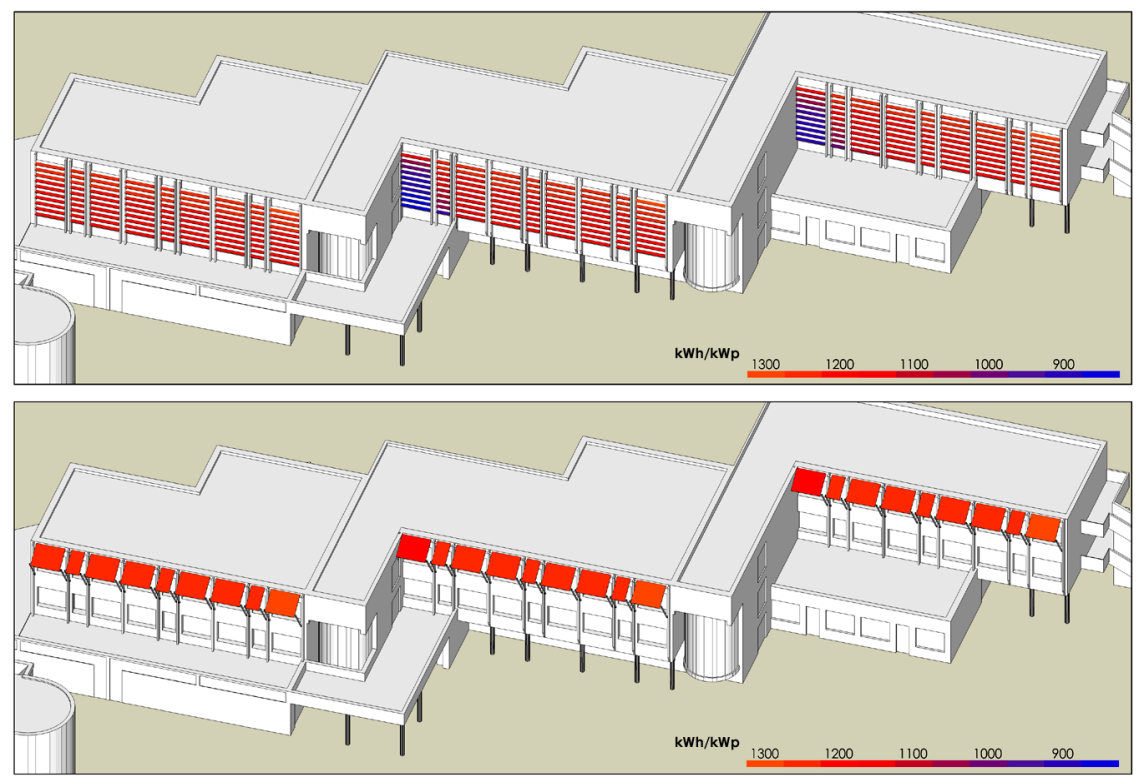

Figure 6: Comparison of energy output between different shading systems. 

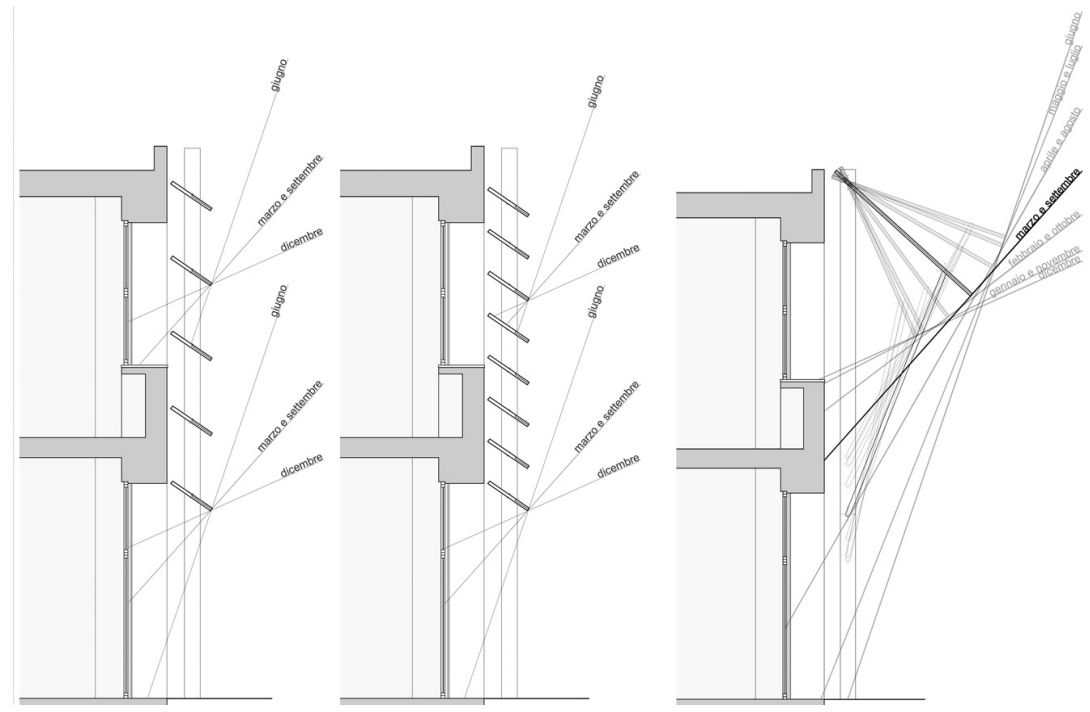

Figure 7: Comparison of shading capacity.

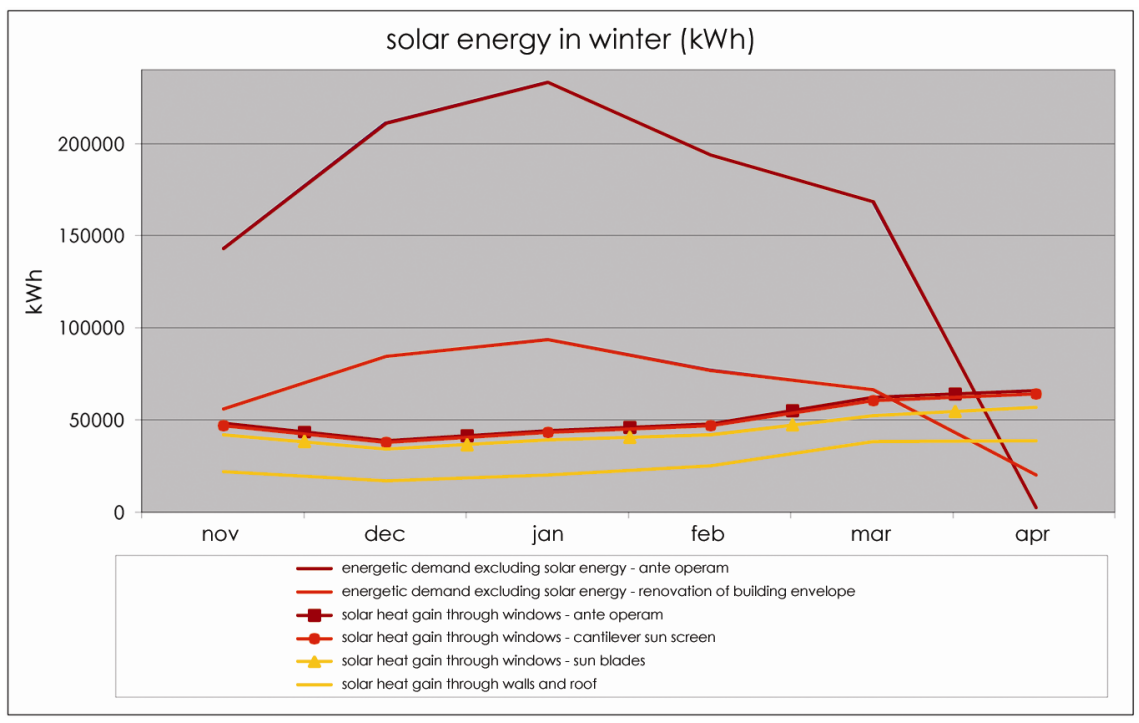

Figure 8: Importance of solar gain in winter.

would form with the sun's rays a greater angle of shade. The cantilever system has a slightly inferior performance in the months of April and August, due principally to the absence of shading on the windows of the lower level, which can be obtained with a secondary shading system necessary also in order to guarantee a complete darkening of the classrooms, if necessary. Should a 
tracking system be employed, there would be notable disadvantages in the winter season, because the need to favor the entrance of thermal radiation would conflict with that of optimizing the energy output: the first, in fact, requires blades parallel to the direction of the sun's rays, the second, perpendicular blades.

Regarding the shading of the luminous radiation, finally, we notice how both systems guarantee a decrement of the daylight factor due to a strong reduction of the direct component. This reduction becomes perhaps excessive in the cantilever solar screen, which in addition represents a poorer distribution of the illuminance which can lead to glare effect. For the purpose of limiting these critical elements - having chosen this solution as the best on the basis of the preceding analyses - it was decided to improve the transparency of the cantilever system (in order to increase the medium daylight factor) utilizing double-glass modules and to install an internal shading that can be accomplished through curtains, which allow the heat to enter and spread direct sunlight.

Table 2: Comparison of indoor natural lighting with different shading systems.

\begin{tabular}{|c|c|c|c|}
\hline & $\begin{array}{c}\text { Ante } \\
\text { operam }\end{array}$ & $\begin{array}{c}\text { Blades solar } \\
\text { screen }\end{array}$ & $\begin{array}{c}\text { Cantilever } \\
\text { solar screen }\end{array}$ \\
\hline Medium daylight factor (Dm) & $5.8 \%$ & $2.3 \%$ & $1.7 \%$ \\
\hline Minimum daylight factor (Dmin) & $2.8 \%$ & $0.8 \%$ & $0.4 \%$ \\
\hline Maximum daylight factor (Dmax) & $17.8 \%$ & $8.0 \%$ & $7.5 \%$ \\
\hline Uniformity factor G1 (Dmin/Dm) & 0.48 & 0.35 & 0.23 \\
\hline Uniformity factor G2 (Dmin/Dmax) & 0.16 & 0.10 & 0.05 \\
\hline
\end{tabular}

\section{Achievements}

The intervention allows the building to reach a class A+ energy label, reducing by roughly $72 \%$ the consumption of energy used for heating, and to improve the comfort conditions in indoor environment during the school year, both in the winter as well as summer season. The requalification furthermore obtains a greater visual comfort, thanks to the improvement in the relation between diffused and direct components, which allows - along with the possibility of shading the thermal radiation in the summer and the luminous rays in winter, without completely closing the shading systems - to estimate a reduction of electrical energy use for lighting which is not exactly quantifiable.

The photovoltaic systems can produce roughly $53.6 \%$ of the building's total requirements, while the $\mathrm{CO} 2$ emissions in the atmosphere are reduced by $68 \%$. The chosen solution furthermore restores the building's image, enriching it with technological elements that in this way are inserted into the didactic instruction as a daily experience of a sustainable lifestyle. 


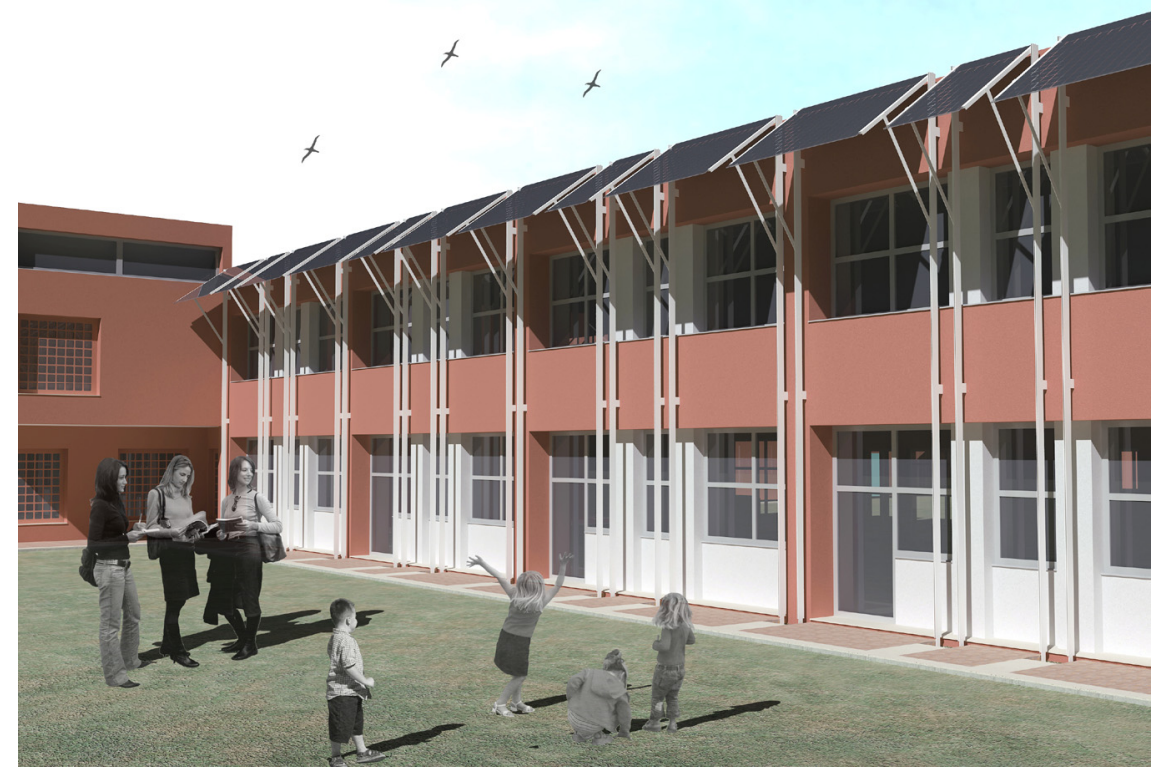

Figure 9: $\quad$ Rendering - south view.

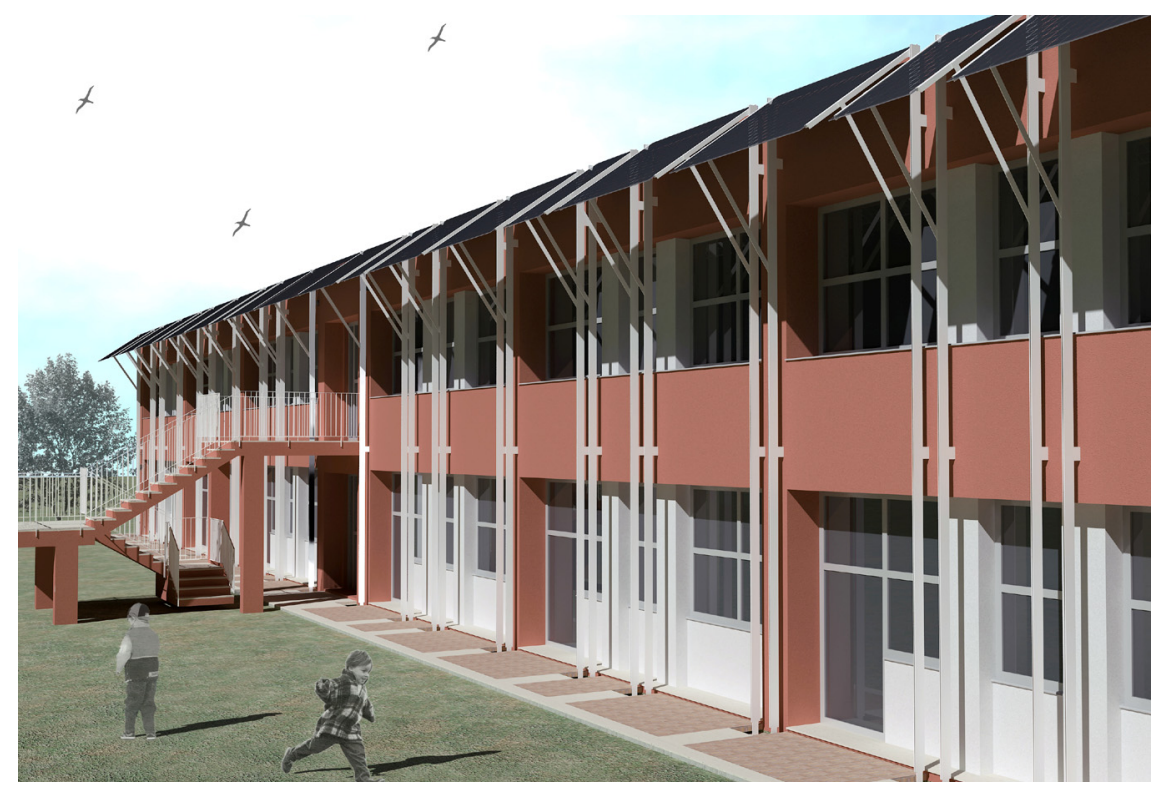

Figure 10: $\quad$ Rendering - south view. 


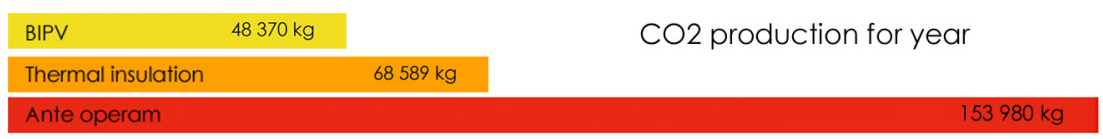

Figure 11: Reduction of $\mathrm{CO} 2$ emission.

\section{References}

[1] European commission, Directorate-general for energy and transport, $E U$ energy and transport in figures - statistical pocketbook, 2009

[2] Citterio, M. \& Fasano, G., Indagine sui consumi degli edifici pubblici (direzionale e scuole) e potenzialità degli interventi di efficienza energetica, ENEA: Roma, 2009

[3] Wargocki, P. \& Wyon, D.P., Effects of HVAC on student performance, ASHRAE journal, October 2006

[4] Source: municipality of Rome, V Department 